\title{
Robust Blind Complex Double Haar Wavelet Transform Based Watermarking Algorithm for Digital Images
}

\author{
S. Maheswari, Member, IACSIT, and K. Rameshwaran
}

\begin{abstract}
Dual-Tree Complex Wavelet Transform is relatively a recent improvement of the Discrete Wavelet Transform (DWT) with important additional properties like shift invariant and directionality. In this paper, we propose a blind watermarking scheme based on Complex Double Haar Wavelet Transform (CDHWT). Single level CDHWT is applied on host image, it decompose the original image into dual nine subbands and single level DHWT is applied to the binary watermark, it decompose the binary image into nine subbands. Eigen values of the selected subband are replaced by the Eigen values of the selected subband of binary watermark which is multiplied by an appropriate strength factor. There is no need of host image and original watermark to extract the watermark from the test image. An experimental result showed that the proposed scheme achieved very high imperceptibility and Robustness against various image processing attacks like JPEG compression, low pass filtering, median filtering, addition of noise, rotation, cropping and histogram equalization etc.
\end{abstract}

Index Terms-M-Channel filter bank, DHWT, CDHWT, SVD and digital watermarking.

\section{INTRODUCTION}

Now a days, digital watermarking plays a major role in multimedia security tools. Because any form of media like image, audio, video and data can be watermarked. Various watermarking methods are proposed for different applications. Novel watermarking techniques are classified into two types, Spatial domain technique and Transform domain technique. In Spatial domain technique [1]-[3], pixel value is directly modified to embed the secret information. In Transform domain technique, Original image is transformed into transform coefficients by using various popular transforms like DCT [4], DFT [5] and DWT [6]-[10] etc. Transform coefficients are modified to embed the secret information. Transform domain technique achieves more robustness as compared to spatial domain technique but it needs more computational complexity.

Due to its multi resolution property, wavelet transform has more application in watermarking on images [6], [7]. Various types of wavelet transforms are employed for different kinds of image watermarking [6]-[10]. Embedding of secret information in different frequency domains has its own advantages and disadvantages. The low-frequency embedding of the watermark increases the robustness with respect to image distortions that have low pass characteristics

Manuscript received August 20, 2011; revised December 7, 2011.

S. Maheswari is with the Kongu Engineering College, Perundurai, Erode-638052, Tamil Nadu, India (e-mail: maheswari_bsb@yahoo.com).

$\mathrm{K}$. Rameshwaran is with the JJ College of Engineering and Technology, Ammapet, Triuchirapalli-620009, Tamil Nadu, India (e-mail: krameshwaran @gmail.com). like filtering, lossy compression, geometrical distortions. On the other hand, low-frequency watermarks are more sensitive to modifications of the histogram, such as contrast/brightness adjustment, gamma correction, histogram equalization, and cropping. Watermarks inserted in high frequencies are typically less robust to low-pass filtering, lossy compression and small geometric deformations of the image. But, they are extremely robust with respect to noise adding, nonlinear deformations of the gray scale. To compromise between these two, mid frequencies are selected to embed the watermark.

Wavelet transform is a very popular technique in image transform. Various watermarking methods are proposed in wavelet domain due to their excellence of multi resolution property. Byun et al. [16] proposed a watermarking method using quantization and statistical characteristics of wavelet transform. Wang et al. [34] proposed a wavelet tree based blind watermarking scheme. Jiang et al. [19] proposed a blind watermarking scheme based on 4-band wavelet transform. An Integer Wavelet Based Multiple Logo-watermarking Scheme was proposed by yuan et al. [31]. Preprocessed watermark is embedded in the low and high frequency subbands. Mahmood et al [32] proposed a semi blind watermarking scheme using image denoiseing based on DWT. Li [35] et al proposed wavelet tree quantization based watermarking scheme robust to geometric attacks like rotation, scaling and cropping. Peng et al [15] proposes a blind image watermarking scheme using wavelet trees quantization. Wei et al [18] proposed a blind watermarking algorithm based on the significant difference of wavelet coefficient quantization.

However, Scalar wavelets are generated by one scaling function [19]. It does not support orthogonality and symmetry simultaneously. Multiwavelets which have more than one scaling function can simultaneously provide better reconstruction while preserving length. Good performance at the boundaries and a high order of approximation are added features. Thus, multiwavelet provides superior performance for image processing applications, compared with scalar wavelets [19]. The Haar wavelet transform consistently outperform the more complex ones when using non-colored watermark [10]. At the same time, DWT suffers from oscillations, shift invariance, aliasing and lack of directionality as it is based on real valued oscillating wavelets.

However, Fourier transform does not suffer from this problem because it is based on complex valued oscillating sinusoids [19]. Therefore, shortcomings of real valued DWT were overcome by the Complex Wavelet Transform [20]. In recent years, Complex Wavelet Transform took more attention in image transformation as well as image 
watermarking [21],[22]. In this paper we propose a Complex Double Haar Wavelet Transform based watermarking scheme. Thus, it combines the advantages of both multiwavelet and complex representation of an image. Section II discusses the M-channel Filter bank and DHWT (Double Haar Wavelet Transform). Section III discusses Complex wavelet transform and CDHWT. Section IV discusses the proposed embedding and extraction algorithm using CDHWT. Section V discusses the experimental result of the proposed algorithm for different gray scale images and comparison with existing DWT based methods followed by conclusion in section VI.

\section{M-CHANNEL FILTER BANK AND DHWT}

Multiwavelet is developed from multiresolution analysis (MRA). The difference is that multiwavelets have several scaling functions whereas MRA have one scaling function. Multiwavelets offer superior performance for image processing applications compared with scalar wavelets [19]. Multi wavelet offers short support, orthogonality, symmetry, and vanishing moments. A multiwavelet system can provide better reconstruction while preserving length, good performance at the boundaries and a high order of approximation. Each multiwavelet system is a matrix valued multirate filterbank. A multiwavelet filterbank has "taps" that are $(N \times N)$ matrices. A filter bank is a structure that decomposes a signal into a collection of subsignals [23]. Depending upon the application, the subsignals help to emphasize specific aspect of the original signal or may be easier to work with than that of the original signal. The structure of a classical filter bank is shown in Fig. 1.

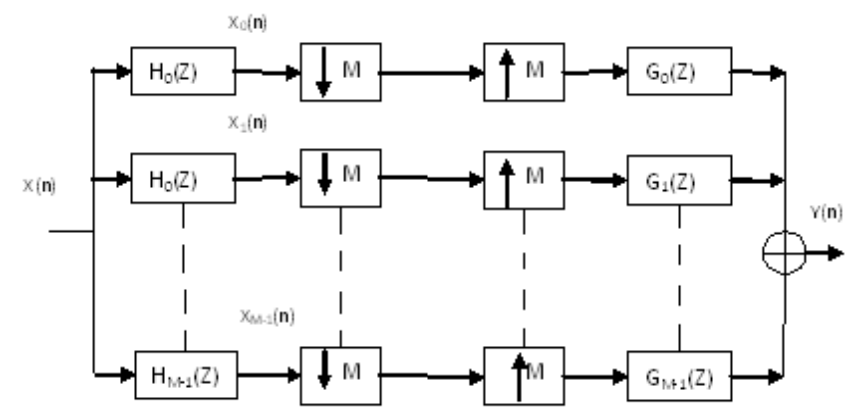

Fig. 1. M-channel filter bank

Perfect Reconstruction Quadrature mirror filters are used to split the input signal into $\mathrm{M}$ subbands which are decimated by $\mathrm{M}$ in signal decomposition. During reconstruction, $\mathrm{M}$ subband signals are decoded, interpolated and recombined using synthesis filters. The Haar Wavelet based M-channel Filter bank (HWF) with $\mathrm{M}=3$ is called the Double Haar Wavelet Transform [24]. The decomposition and Reconstruction filter banks are defined as follows:

$$
H=\frac{1}{3}\left(\begin{array}{ccc}
1 & -1 & 0 \\
0 & 1 & -1 \\
1 & 1 & 1
\end{array}\right) \quad G=\left(\begin{array}{ccc}
2 & 1 & 1 \\
-1 & 1 & 1 \\
-1 & -2 & 1
\end{array}\right)
$$

Similar to the two dimensional (2-D) orthogonal wavelet transform, the DHWT can also be extended to 2-D signals. Let $\mathrm{x}_{0}(\mathrm{~m}, \mathrm{n})$ be an image of $\mathrm{N} \times \mathrm{N}$ pixels. The steps of the 2-D discrete double Haar wavelet transform are defined by the following steps [20].
Step 1: In the horizontal direction, the original image $x_{0}(m, n)$ is filtered by the filters $H_{0}(z) H_{1}(z)$ and $H_{2}(z)$ respectively. Three images $x_{00}^{\prime}(m, n) x_{01}^{\prime}(m, n)$ and $x_{02}^{\prime}(m, n)$ are produced.

Step 2: In the vertical direction, the three images $x_{00}^{\prime}(m, n) x_{01}^{\prime}(m, n)$ and $x_{02}^{\prime}(m, n)$ are filtered by the filters $H_{0}(z), H_{1}(z)$ and $H_{2}(z)$ respectively. This gives nine images $x_{0 j}^{n}(m, n) 0 \leq j \leq 8$.

Step 3: Down-sampling the images $x_{0 j}^{\prime \prime}(m, n) 0 \leq j \leq 8$, with an interval of three, we obtain nine subimages $x_{0 j}(m, n) 0 \leq j \leq 8$.

Step 4: Steps 1 to 3 can be repeated on the subimage $x_{00}(m, n)$ so as to get the other subimages in the next scale.

In two-dimensional DHWT, each level of decomposition produces nine bands of data. The low pass band can further be decomposed to obtain another level of decomposition. Fig. 2 shows the first level of decomposition.

\begin{tabular}{|l|l|l|}
\hline$x_{00}$ & $x_{01}$ & $x_{02}$ \\
\hline$x_{10}$ & $x_{11}$ & $x_{12}$ \\
\hline$x_{20}$ & $x_{21}$ & $x_{22}$ \\
\hline \multicolumn{2}{|c|}{ Fig. 2. 1-level DHWT } \\
\hline
\end{tabular}

\section{COMPLEX WAVElEt TRANSFORM AND CDHWT}

DWT suffers from oscillations, shift invariance, aliasing and lack of directionality as it is based on real valued oscillating wavelets. However, Fourier transform does not suffer from this problem. Because, it is based on complex valued oscillating sinusoids. Therefore, shortcomings of real valued DWT are overcome by the Complex wavelet transform.

CWT can be obtained from Hilbert transform, oscillating cosine and sine components form a Hilbert transform pair as they are $90^{\circ}$ out of phase with each other. Hilbert transform is applied to the data. The real wavelet transform was applied to both the original data and the Hilbert transformed data and the coefficients of each wavelet transform were combined to obtain a CWT. Ideal Hilbert transform in conjunction with the wavelet transform effectively increased the support of the wavelets.

One effective approach for implementing an analytic wavelet transform, first introduced by Kingsbury in 1998, was called the Dual-Tree CWT. The Dual Tree CWT employed two real DWTs [2]. The first DWT gives the real part of the transform while the second DWT gives the imaginary part. The analysis and synthesis FBs used to implement the dual-tree CWT and its inverse was illustrated in Figs. 3 and 4.

In this paper, we present a Complex Double Haar Wavelet Transform that combines the advantages of both CWT and M-Channel filter bank. Similar to Dual tree complex wavelet transform CDHWT is also implemented with dual DHWT. $H_{0}(n), H_{1}(n)$ and $H_{2}(n)$ are the analysis filter banks gives the real part of DHWT. $G_{0}(n), G_{1}(n)$ and $G_{2}(n)$ are the analysis filter banks gives the imaginary part of DHWT. The analysis and synthesis filter banks used to implement the dual-tree CDHWT and its inverse are illustrated in Figs. 5 and 6. 


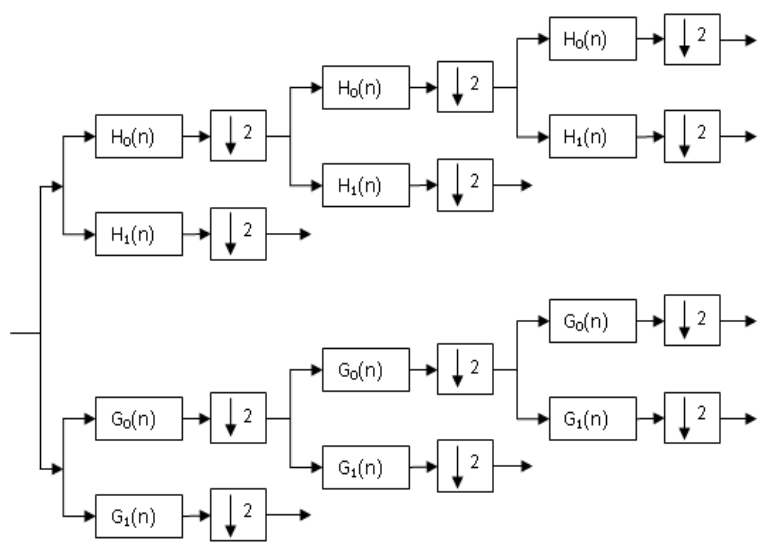

Fig. 3. Analysis filter bank for the dual-tree discrete CWT

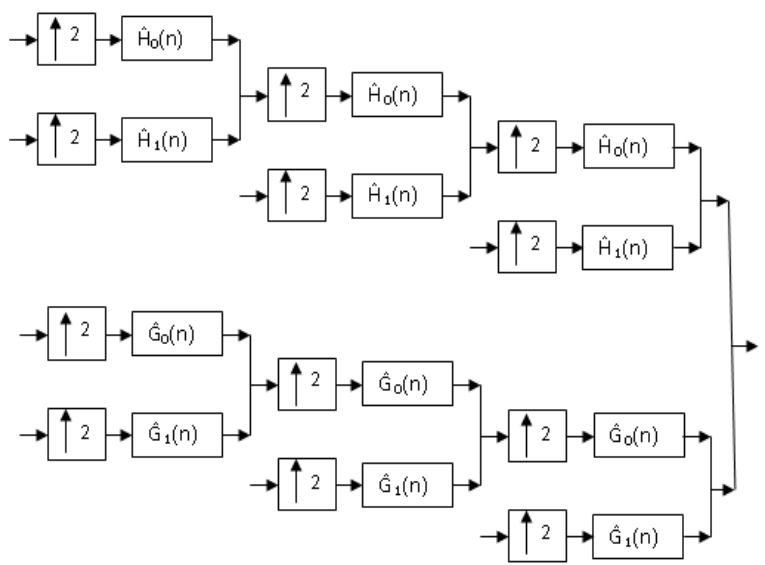

Fig. 4. Synthesis filter bank for the dual-tree discrete CWT

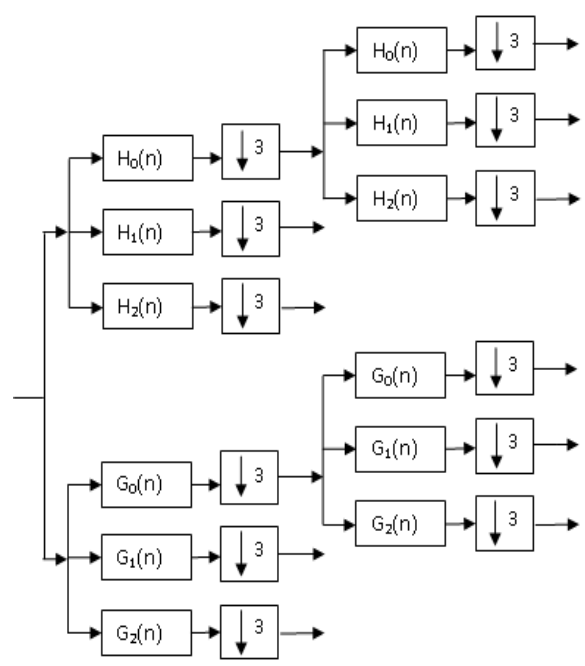

Fig. 5. Analysis filter bank for the CDHWT

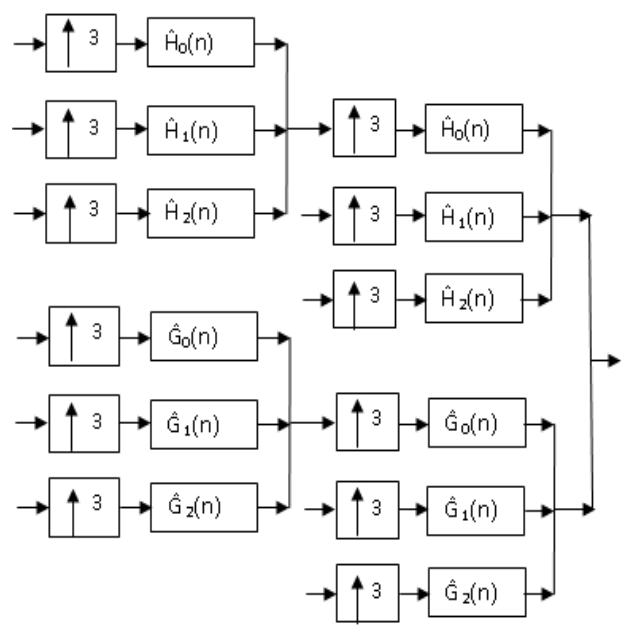

Fig.6. Synthesis filter bank for the CDHWT

\section{Proposed SCHEME}

\section{A. Embedding Algorithm}

A single level CDHWT is applied on the original image $X$ $(i, j)$ and binary watermark image. Singular value decomposition [25],[26] is taken on the subbands $X_{11}$ of the subband and $X_{11 w}$ of the binary watermark to obtain their Eigen values $\left(\sigma, \sigma_{w}\right)$. The Eigen values $\sigma$ of the host image is replaced by the eigen values $\sigma_{w}$ of the watermark image after multiplying with the proper strength factor. Then inverse SVD and Complex DWT were applied to obtain the watermarked image $X(i, j)^{*}$.

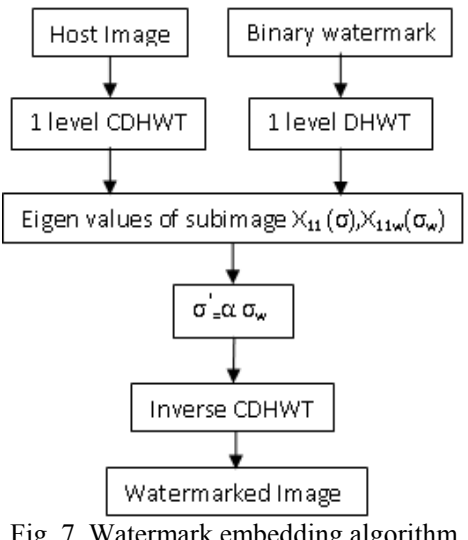

\section{B. Extraction Algorithm}

In this paper, we proposed the blind watermarking scheme. Original image and Original watermark are not required to extract the secret message. A one level CDHWT is applied on the test image and their Eigen values of selected sub image are obtained by using SVD. Eigen values are divide with the strength factor in order to extract the binary watermark. Then the extracted watermark is compared with the original watermark, to check whether the test image should contain the watermark or not by measuring the normalized correlation between them.

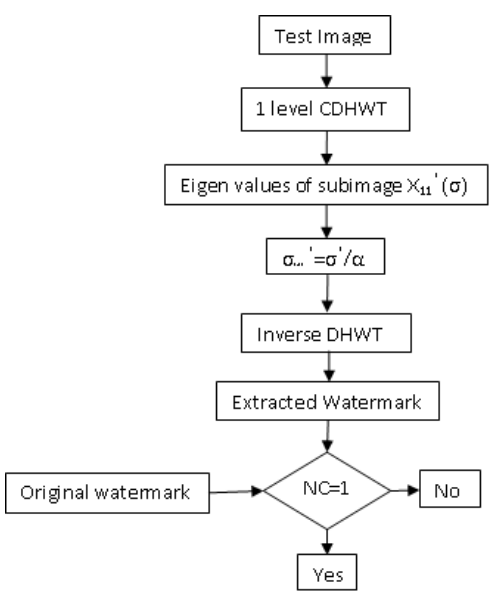

Fig. 8. Watermark extraction algorithm

\section{EXPERIMENTAL RESULTS}

The experiments were performed on different gray scale images such as Lena, Baboon, Boat, Fruits, Circles, Rose, and Girl etc. Binary watermark image is of size $33 \times 33$. A 1-level CDHWT is applied on the Lena image. A mid frequency band $\left(X_{11}{ }^{\prime} \mathrm{s}\right)$ is selected to embed the watermark. A watermarked Lena image is having PSNR value of 50.9419 
with no perceptibility problem on watermarked image when using $\alpha$ at 275 (Lena image). Fig. 9 shows the cover image, original watermark, watermarked image and the extracted watermark.

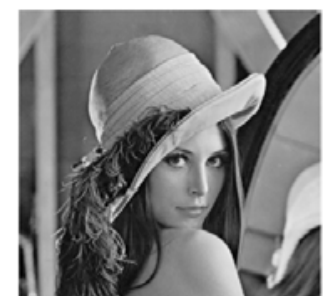

(a)

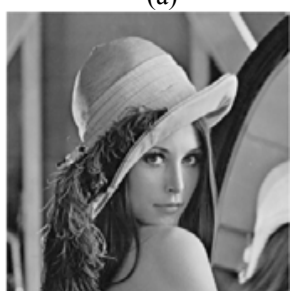

(c)

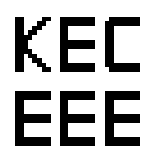

(b)

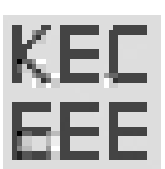

(d)
Fig. 9. (a) Cover image; (b) Original Watermark;

(c) Watermarked Image; (d) Extracted Watermark

Any watermarking system should be robust against various image processing attacks. It should not be removable by unauthorized users and it should not degrade the quality of the images. There are many attacks against which image watermarking system could be judged. The attacks include JPEG compression, average filtering, rotation, median filtering, Salt and Pepper noise, Gaussian noise, speckle noise and so on. These attacks are applied to the watermarked images to evaluate recovery process. Mean Square Error (MSE), PSNR (Peak Signal to Noise Ratio) and NC (Normalized Cross-Correlation) are used to estimate the quality of extracted watermark. MSE, PSNR and NC [7, 9] are defined as following,

$$
P S N R=10 \log _{\frac{255^{2}}{M S E}}
$$

where MSE is defined as follows,

$$
M S E=\frac{1}{m n} \sum_{X=1}^{m} \sum_{Y=1}^{n}(f(x, y)-\hat{f}(x, y))^{2}
$$

where $m$ and $n$ are size of images, and $f(x, y)$ and $\hat{f}(x, y)$ are value at $(\mathrm{x}, \mathrm{y})$ location of the host and watermarked image,

$$
N C=\frac{\sum_{i} \sum_{j} p_{i j} p_{i j}^{*}}{\sum_{i} \sum_{j}\left(p_{i j}\right)^{2}} \ldots
$$

where and $p_{i j}$ and $p_{i j}^{*}$ are pixel values at $(i, j)^{\text {th }}$ location of the original and recovered watermark patterns respectively.

\begin{tabular}{lcc}
\multicolumn{3}{c}{ TABLE I: PSNR VALUES OF WATERMARKED IMAGE } \\
\hline Image Type & PSNR in db & Normalized Correlation \\
\hline Lena & 50.9419 & 0.9961 \\
Baboon & 37.2311 & 0.9958 \\
Boat & 40.1335 & 0.9984 \\
Fruits & 39.1722 & 0.9975 \\
Rose & 41.0753 & 0.9984 \\
Girl & 39.5898 & 0.9991 \\
Moon & 50.2254 & 0.9977 \\
Cameraman & 43.3518 & 0.9943 \\
Rohith & 44.3346 & 0.9995 \\
Circuit & 31.985 & 0.9382 \\
Circles & 35.658 & 0.98 \\
\hline
\end{tabular}

PSNR values obtained for various gray scale images are shown in the Table I.

\section{A. Robustness to Noise}

Robustness to noise is very important in watermarking algorithms. Four kinds of noises were tested. Zero mean Gaussian noise with variance $100,1 \%$ salt and pepper noise, Poisson and speckle noise.

\begin{tabular}{lcccc}
\multicolumn{4}{c}{ TABLE II: NC UNDER VARIOUS NoISE CONDITION } \\
\hline \hline \multirow{4}{*}{ Image Type } & \multicolumn{4}{c}{ Addition of Noise } \\
& Gaussian & Salt\&Pepper & Poisson & Speckle \\
\hline Lena & 0.9904 & 0.9905 & 0.9903 & 0.9905 \\
Baboon & 0.9904 & 0.9904 & 0.9903 & 0.9904 \\
Boat & 0.9904 & 0.9904 & 0.9903 & 0.9904 \\
Fruits & 0.9904 & 0.9904 & 0.9903 & 0.9904 \\
Rose & 0.9904 & 0.9905 & 0.9903 & 0.9904 \\
Girl & 0.9905 & 0.9905 & 0.9905 & 0.9905 \\
Moon & 0.991 & 0.9911 & 0.9911 & 0.991 \\
Cameraman & 0.9904 & 0.9905 & 0.9903 & 0.9905 \\
Rohith & 0.9904 & 0.9905 & 0.9903 & 0.9905 \\
Circuit & 0.9906 & 0.9906 & 0.9906 & 0.9906 \\
Circles & 0.9911 & 0.9911 & 0.9911 & 0.9911 \\
\hline \hline
\end{tabular}

The simulated results of the Normalized Correlation under Various noises are shown in Table II. Fig.10 demonstrates that this algorithm is robust to noise.

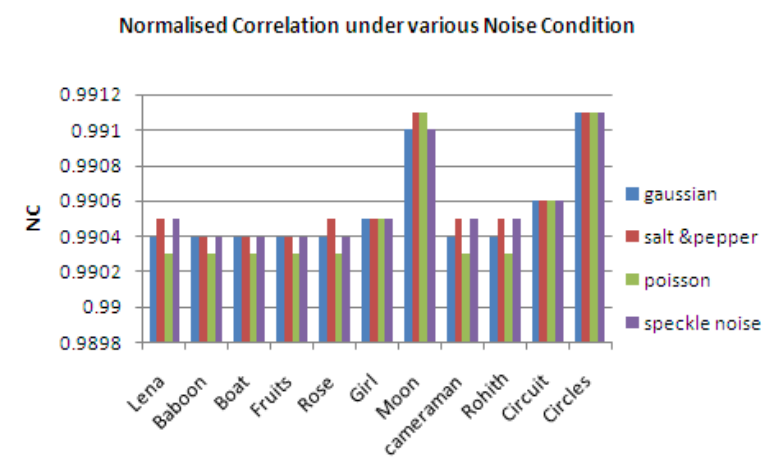

Fig. 10. NC under various Noise Conditions

\section{B. Robustness to Image Processing Attacks}

The watermarking algorithm is also robust to image processing techniques. The popular image processing attacks are histogram equalization, JPEG compression and filtering. The correlation computed from histogram equalized images is shown in Table III. From the results shown in Fig.11 the proposed algorithm is robust to histogram equalization.

TABLE III: NC UNDER HisTOGRAM EQUALIZATION

\begin{tabular}{lc}
\hline \hline Image Type & Histogram Equalization \\
\hline Lena & 0.9903 \\
Baboon & 0.9903 \\
Boat & 0.9904 \\
Fruits & 0.9904 \\
Rose & 0.9904 \\
Girl & 0.9905 \\
Moon & 0.991 \\
Cameraman & 0.9904 \\
Rohith & 0.9904 \\
Circuit & 0.9906 \\
Circles & 0.991 \\
\hline \hline
\end{tabular}

Watermarked image has been compressed using JPEG 
compression with different quality factor as shown in Table IV. A range of QF is typically 1 to 100 . As demonstrated in Fig. 12 the proposed method is highly robust against JPEG compression with different quality factor in between 1 to 100 .

TABLE IV: NC UNDER JPEG COMPRESSION

\begin{tabular}{lccccc}
\hline \hline \multirow{2}{*}{ Image Type } & \multicolumn{5}{c}{ Addition of Noise } \\
& 1 & 3 & 5 & 10 & 20 \\
\hline Lena & 0.9903 & 0.9903 & 0.9903 & 0.9903 & 0.9903 \\
Baboon & 0.9946 & 0.9944 & 0.9944 & 0.9944 & 0.9944 \\
Boat & 0.9946 & 0.9944 & 0.9944 & 0.9944 & 0.9944 \\
Fruits & 0.9946 & 0.9944 & 0.9944 & 0.9944 & 0.9944 \\
Rose & 0.9935 & 0.9934 & 0.9934 & 0.9934 & 0.9934 \\
Girl & 0.9934 & 0.9935 & 0.9935 & 0.9935 & 0.9935 \\
Moon & 0.838 & 0.8381 & 0.8381 & 0.8381 & 0.8381 \\
Cameraman & 0.9486 & 0.9484 & 0.9484 & 0.9484 & 0.9484 \\
Rohith & 0.9698 & 0.9697 & 0.9697 & 0.9697 & 0.9697 \\
Circuit & 0.9363 & 0.9362 & 0.9362 & 0.9362 & 0.9361 \\
\hline \hline
\end{tabular}

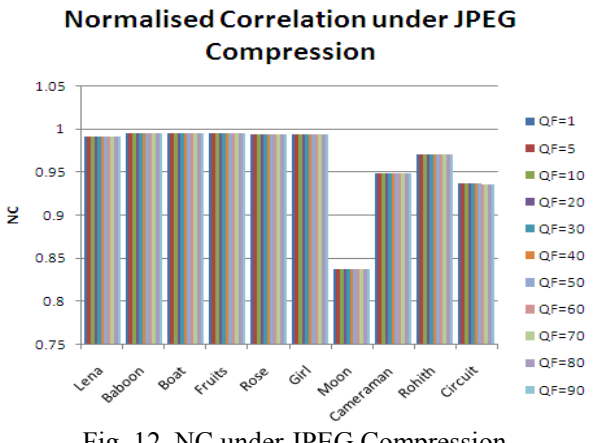

Fig. 12. NC under JPEG Compression

Another popular image processing tool is filter. Two types of filters are tested. Low pass filter and Median filter, which can be considered as case of pixel permutation. The simulated results of the Normalized Correlation for the above mentioned two filtering Conditions are shown in the Table $\mathrm{V}$ and Table VI.

TABLE V: NC UNDER AVERAgE FILTERING

\begin{tabular}{lcccccc}
\hline \hline \multirow{2}{*}{ Image Type } & $3 \times 3$ & $5 \times 5$ & $7 \times 7$ & $9 \times 9$ & $11 \times 111$ & $15 \times 15$ \\
\hline Lena & 0.9939 & 0.9925 & 0.9918 & 0.9915 & 0.9912 & 0.9910 \\
Baboon & 0.9933 & 0.9917 & 0.9911 & 0.9909 & 0.9908 & 0.9906 \\
Boat & 0.993 & 0.992 & 0.9914 & 0.991 & 0.9908 & 0.9909 \\
Fruits & 0.9932 & 0.9919 & 0.9913 & 0.991 & 0.9909 & 0.9907 \\
Rose & 0.9931 & 0.9921 & 0.9915 & 0.9912 & 0.991 & 0.9908 \\
Girl & 0.9932 & 0.992 & 0.9915 & 0.9912 & 0.991 & 0.9907 \\
Moon & 0.9933 & 0.9923 & 0.9918 & 0.9915 & 0.9912 & 0.9909 \\
Cameraman & 0.9937 & 0.9926 & 0.9919 & 0.9915 & 0.9912 & 0.9909 \\
Rohith & 0.9923 & 0.9914 & 0.9911 & 0.9909 & 0.9908 & 0.9907 \\
Circuit & 0.9888 & 0.994 & 0.9931 & 0.9923 & 0.9917 & 0.9911 \\
Circles & 0.9946 & 0.9946 & 0.9938 & 0.993 & 0.9925 & 0.9917 \\
\hline \hline
\end{tabular}

TABLE VI: NC under MEDIAN FiLtering

\begin{tabular}{lcccccc}
\hline \multirow{2}{*}{ Image Type } & \multirow{6}{c}{ Median Filtering } \\
& $3 \times 3$ & $5 \times 5$ & $7 \times 7$ & $9 \times 9$ & $11 \times 11$ & $15 \times 15$ \\
\hline Lena & 0.9942 & 0.9944 & 0.9939 & 0.995 & 0.9934 & 0.9948 \\
Baboon & 0.9936 & 0.994 & 0.9925 & 0.9942 & 0.9939 & 0.9949 \\
Boat & 0.9939 & 0.9946 & 0.9933 & 0.9954 & 0.9944 & 0.996 \\
Fruits & 0.994 & 0.9944 & 0.9937 & 0.9941 & 0.9929 & 0.9939 \\
Rose & 0.9942 & 0.9939 & 0.9944 & 0.9937 & 0.9934 & 0.9934 \\
Girl & 0.9939 & 0.994 & 0.9929 & 0.9944 & 0.9945 & 0.9958 \\
Moon & 0.9938 & 0.9936 & 0.9936 & 0.9935 & 0.9933 & 0.9934 \\
Cameraman & 0.9941 & 0.9949 & 0.9938 & 0.9952 & 0.9939 & 0.9954 \\
Rohith & 0.9946 & 0.9948 & 0.9939 & 0.9963 & 0.9946 & 0.9968 \\
Circuit & 0.9767 & 0.9921 & 0.9958 & 0.9967 & 0.9971 & 0.9982 \\
Circles & 0.9882 & 0.9879 & 0.9899 & 0.9889 & 0.9896 & 0.9902 \\
\hline \hline
\end{tabular}

Figs. 13 and 14 show the experiment results of various gray scale images under filter attacks. We also see that this scheme can resist filter attacks under different window size.

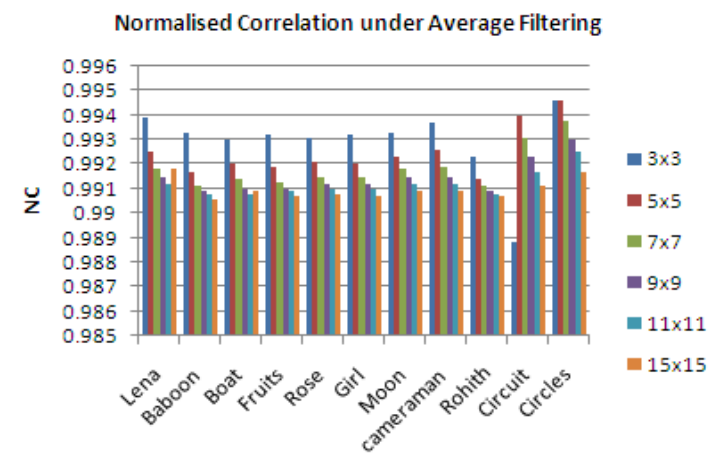

Fig. 13. NC under Average filtering

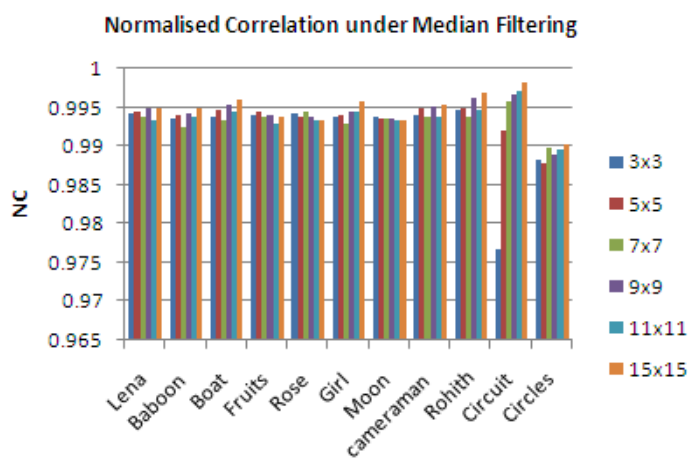

Fig. 14. NC under Median filtering

\section{Robustness to Geometric attacks}

Robust against Digital watermarking to geometric attacks is a difficult one that constrains the practical value of watermarking technique. Geometric attacks include rotation, cropping and scaling etc. The correlations computed for various gray scale images under cropping attack are shown in Table VII.

\begin{tabular}{ll} 
TABLE VII: NC UNDER CROPPING OF AN IMAGE \\
\hline \hline Image Type & Cropping \\
\hline Lena & 0.9921 \\
Baboon & 0.9948 \\
Boat & 0.995 \\
Fruits & 0.9954 \\
Rose & 0.9954 \\
Girl & 0.9959 \\
Moon & 0.9939 \\
Cameraman & 0.9949 \\
Rohith & 0.9921 \\
Circuit & 0.996 \\
Circles & 0.9947 \\
\hline \hline
\end{tabular}

TABLE VIII: NC UNDER VARIOUS ANGLES OF ROTATION

\begin{tabular}{lccccccc}
\hline \hline Image Type & $\mathbf{1 5}^{\circ}$ & $\mathbf{3 0}^{\circ}$ & $\mathbf{4 5}^{\circ}$ & $\mathbf{6 0}^{\circ}$ & $\mathbf{9 0}^{\circ}$ & $\mathbf{1 8 0}^{\circ}$ & $\mathbf{2 7 0}^{\circ}$ \\
Moon & 0.9935 & 0.9932 & 0.9931 & 0.993 & 0.9921 & 0.992 & 0.992 \\
Lena & 0.9941 & 0.9934 & 0.9933 & 0.9934 & 0.9884 & 0.989 & 0.989 \\
Rohith & 0.9944 & 0.9938 & 0.9934 & 0.994 & 0.9937 & 0.9941 & 0.9939 \\
Rose & 0.9946 & 0.9942 & 0.9936 & 0.9939 & 0.9929 & 0.9926 & 0.9927 \\
Cameraman & 0.9944 & 0.9946 & 0.9951 & 0.9946 & 0.9935 & 0.9936 & 0.9943 \\
Girl & 0.9947 & 0.9953 & 0.9951 & 0.9951 & 0.9949 & 0.9948 & 0.9947 \\
Boat & 0.9937 & 0.9937 & 0.9937 & 0.9936 & 0.9932 & 0.9932 & 0.9932 \\
Fruits & 0.9931 & 0.9914 & 0.9904 & 0.9906 & 0.989 & 0.9888 & 0.9892 \\
Baboon & 0.9937 & 0.9935 & 0.9935 & 0.9936 & 0.9943 & 0.9942 & 0.9961 \\
Circles & 0.9514 & 0.9633 & 0.9635 & 0.9564 & 0.893 & 0.8727 & 0.8799 \\
Circuit & 0.9736 & 0.9648 & 0.9548 & 0.9652 & 0.9422 & 0.9444 & 0.9552 \\
\hline
\end{tabular}


The simulated results of the Normalized Correlation under various angles of rotation are shown in Table VIII. One can note that this scheme can resist rotational attacks under various angles of rotation.

From the results shown in Figs. 15 and 16 the proposed algorithm is robust to geometric attacks.

Table IX shows the image results of extracted watermark from the Lena image under various attacks. The proposed watermarking scheme is compared with existing recently published papers by Byun et al [11], Wang et al [12], Jiang et al. [13], yuan et al. [14], Mahmood et al [15], Li [16] et al, Peng et al [17] and Wei et al [18] based on lena image, the results are shown in Tables X-XII.

\begin{tabular}{|c|c|c|c|c|c|}
\hline \multicolumn{4}{|c|}{ Addition of Noise } & \multirow{2}{*}{$\begin{array}{c}\begin{array}{c}\text { JPEG } \\
\text { Compression }\end{array} \\
\text { QF }=10 \\
\text { KEC } \\
\text { EEE } \\
\mathrm{NC}=0.9903\end{array}$} & \multirow{2}{*}{$\begin{array}{c}\begin{array}{c}\text { Histogram } \\
\text { Equalization }\end{array} \\
\text { KEC } \\
\text { EEE } \\
\mathrm{NC}=0.9903\end{array}$} \\
\hline $\begin{array}{c}\text { Gaussian } \\
\text { KEC } \\
\text { EEE } \\
\text { NC }=0.9904\end{array}$ & $\begin{array}{c}\text { Salt and Pepper } \\
\text { KEC } \\
\text { EEE } \\
\mathrm{NC}=0.9905\end{array}$ & $\begin{array}{c}\text { Poisson } \\
\text { KEE } \\
\text { EEE } \\
\mathrm{NC}=0.9903\end{array}$ & $\begin{array}{c}\text { Speckle } \\
\text { KEL } \\
\text { EEE } \\
\mathrm{NC}=0.9903\end{array}$ & & \\
\hline \multicolumn{6}{|c|}{ Low Pass Filtering } \\
\hline $\begin{array}{c}3 \times 3 \\
\text { KEE } \\
\mathrm{EEE} \\
\mathrm{NC}=0.9939\end{array}$ & $\begin{array}{c}5 \times 5 \\
\text { KEE } \\
\text { EEE } \\
\mathrm{NC}=0.9925\end{array}$ & $\begin{array}{c}7 \times 7 \\
\text { KEC } \\
\text { EEE } \\
N C=0.9918\end{array}$ & $\begin{array}{c}9 \times 9 \\
\text { KEE } \\
\text { EEE } \\
N C=0.9915\end{array}$ & $\begin{array}{c}11 \times 11 \\
\text { KEE } \\
\text { EEE } \\
\mathrm{NC}=0.9912\end{array}$ & $\begin{array}{c}15 \times 15 \\
\text { KEC } \\
\text { EEE } \\
\mathrm{NC}=0.9910\end{array}$ \\
\hline \multicolumn{6}{|c|}{ Median Filtering } \\
\hline $\begin{array}{c}3 \times 3 \\
\text { KEE } \\
\mathrm{EEE} \\
\mathrm{NC}=0.9942\end{array}$ & $\begin{array}{c}5 \times 5 \\
\text { KEE } \\
\text { EEE } \\
\mathrm{NC}=0.9944\end{array}$ & $\begin{array}{c}7 \times 7 \\
\text { KEE } \\
\text { EEE } \\
N C=0.9939\end{array}$ & $\begin{array}{c}9 \times 9 \\
\text { KEE } \\
\text { EEE } \\
\mathrm{NC}=0.995\end{array}$ & $\begin{array}{c}11 \times 11 \\
\text { KEC } \\
\text { EEE } \\
\mathrm{NC}=0.9934\end{array}$ & $\begin{array}{c}15 \times 15 \\
\text { KEE } \\
\text { EEE } \\
\mathrm{NC}=0.9948\end{array}$ \\
\hline \multicolumn{6}{|c|}{ Rotation } \\
\hline $\begin{array}{l}\alpha=0.25 \\
\text { KEC } \\
\text { EEE }\end{array}$ & $\begin{array}{l}\alpha=0.5 \\
\text { KEE } \\
\text { EEE }\end{array}$ & $\begin{array}{l}\alpha=0.75 \\
\text { KEC } \\
\text { EEE }\end{array}$ & $\begin{array}{c}\alpha=1 \\
\text { KEC } \\
\text { EEE }\end{array}$ & $\begin{array}{l}\alpha=15 \\
\text { KEC } \\
\text { EEE }\end{array}$ & $\begin{array}{l}\alpha=30 \\
\text { KEE } \\
\text { EEE }\end{array}$ \\
\hline $\mathrm{NC}=0.9942$ & $\mathrm{NC}=0.9939$ & $\mathrm{NC}=0.9939$ & $\mathrm{NC}=0.9937$ & $\mathrm{NC}=0.9936$ & $\mathrm{NC}=0.9935$ \\
\hline$\alpha=45$ & $\alpha=60$ & $\alpha=90$ & $\alpha=180$ & $\alpha=270$ & Cropping \\
\hline $\begin{array}{l}\text { KEE } \\
\text { EEE }\end{array}$ & $\begin{array}{l}\text { KEC } \\
\text { EEE }\end{array}$ & $\begin{array}{l}\text { KEE } \\
\text { EEE }\end{array}$ & $\begin{array}{l}\text { KEE } \\
\text { EEE }\end{array}$ & $\begin{array}{l}\text { KEE } \\
\text { EEE }\end{array}$ & $\begin{array}{l}\text { KEE } \\
\text { EEE }\end{array}$ \\
\hline $\mathrm{NC}=0.9933$ & $\mathrm{NC}=0.9934$ & $\mathrm{NC}=0.9938$ & $\mathrm{NC}=0.9936$ & $\mathrm{NC}=0.9936$ & $\mathrm{NC}=0.9921$ \\
\hline
\end{tabular}

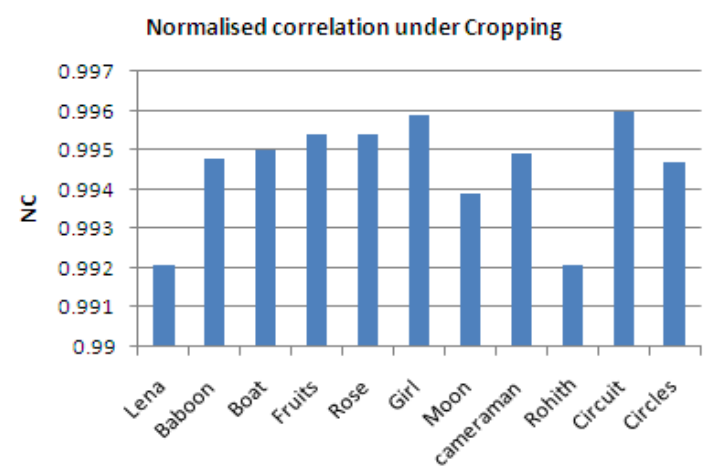

Fig. 15. NC under cropping

Normalised Correlation under various Angles of Rotation

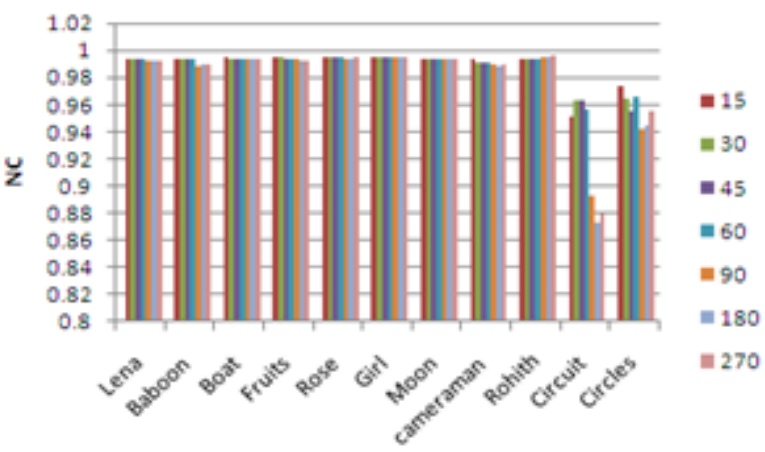

Fig.16. NC under various angles of rotation
TABLE X: Comparison of PSNR VALUe of Watermarked IMAge IN Proposed Method and Existing Methods

\begin{tabular}{ll}
\hline \hline Methods & PSNR in db \\
\hline Byun et al & 41.95 \\
Wang et al & 38.2 \\
Jiang et al. & 40.263 \\
Mahmood et al & 45.1 \\
Li et al, & 40.6 \\
Peng et al & 38.764 \\
Wei et al & 44.25 \\
Proposed method & 50.9419 \\
\hline \hline
\end{tabular}

TABLE XI: Comparison of Proposed MEthod and Existing Methods Under Image Processing AtTaCks

(a) JPEG COMPRESSION

\begin{tabular}{ccccccc}
\hline \hline $\begin{array}{c}\text { JPEG } \\
\text { Compression }\end{array}$ & $\begin{array}{c}\text { Mahmood } \\
\text { et al }\end{array}$ & $\begin{array}{c}\text { Byun et } \\
\text { al. }\end{array}$ & $\begin{array}{c}\text { Wang } \\
\text { et al. }\end{array}$ & $\begin{array}{c}\text { Lein and } \\
\text { Lin }\end{array}$ & $\begin{array}{c}\text { Wei } \\
\text { et al }\end{array}$ & $\begin{array}{c}\text { Proposed } \\
\text { method }\end{array}$ \\
\hline $\mathrm{QF}=30 \%$ & & 0.7654 & 0.15 & & 0.87 & 0.9903 \\
$\mathrm{QF}=40 \%$ & & 0.8148 & 0.23 & 0.828 & 0.95 & 0.9903 \\
$\mathrm{QF}=50 \%$ & & 0.8333 & 0.26 & 0.916 & 0.98 & 0.9903 \\
$\mathrm{QF}=70 \%$ & 0.81 & 0.9383 & 0.57 & 0.928 & 1 & 0.9903 \\
$\mathrm{QF}=80 \%$ & 0.89 & 0.9691 & & 0.945 & 1 & 0.9903 \\
$\mathrm{QF}=90 \%$ & 0.97 & 0.9938 & 1 & & 1 & 0.9903 \\
\hline \hline
\end{tabular}

(b)MEdian FiLTERING

\begin{tabular}{|c|c|c|c|c|c|c|c|}
\hline $\begin{array}{c}\text { Median } \\
\text { Filter }\end{array}$ & $\begin{array}{l}\mathrm{Li} e t \\
\text { al. }\end{array}$ & $\begin{array}{l}\text { Wang } \\
\text { et al }\end{array}$ & $\begin{array}{l}\text { Lein and } \\
\text { Lin }\end{array}$ & $\begin{array}{c}\text { Mahmood } \\
\text { et al }\end{array}$ & $\begin{array}{l}\text { Jiang } \\
\text { et al }\end{array}$ & $\begin{array}{l}\text { Wei } \\
\text { et al }\end{array}$ & $\begin{array}{c}\text { Proposed } \\
\text { method }\end{array}$ \\
\hline $3 \times 3$ & 0.35 & 0.51 & $\begin{array}{l}0.89 \\
\end{array}$ & 0.92 & 0.9962 & 0.88 & 0.9942 \\
\hline
\end{tabular}


(c) AdDition of GaUssian NoISE

\begin{tabular}{ccccccccc}
\hline \hline & $\begin{array}{c}\text { Yuan } \\
\text { et al. }\end{array}$ & $\begin{array}{c}\text { Wang } \\
\text { et al }\end{array}$ & $\begin{array}{c}\text { Li } \text { et } \\
\text { al }\end{array}$ & $\begin{array}{c}\text { lein and } \\
\text { lin }\end{array}$ & $\begin{array}{c}\text { Jiang } \\
\text { et al }\end{array}$ & $\begin{array}{c}\text { Mah } \\
\text { mood et al }\end{array}$ & $\begin{array}{c}\text { Wei } \\
\text { et al }\end{array}$ & $\begin{array}{c}\text { Proposed } \\
\text { method }\end{array}$ \\
\hline $\begin{array}{c}\text { Gaussian } \\
\text { Noise }\end{array}$ & 0.546 & 0.64 & 0.7 & 0.768 & 0.9596 & 1 & 0.91 & 0.9904 \\
\hline \hline
\end{tabular}

(d) Histogram Equalization

\begin{tabular}{ccccc}
\hline \hline & Yuan et al & Lian and Lin & Wei et al & Proposed Method \\
\hline $\begin{array}{c}\text { Histogram } \\
\text { Equalization }\end{array}$ & 0.616 & 0.935 & 0.77 & 0.9903 \\
\hline \hline
\end{tabular}

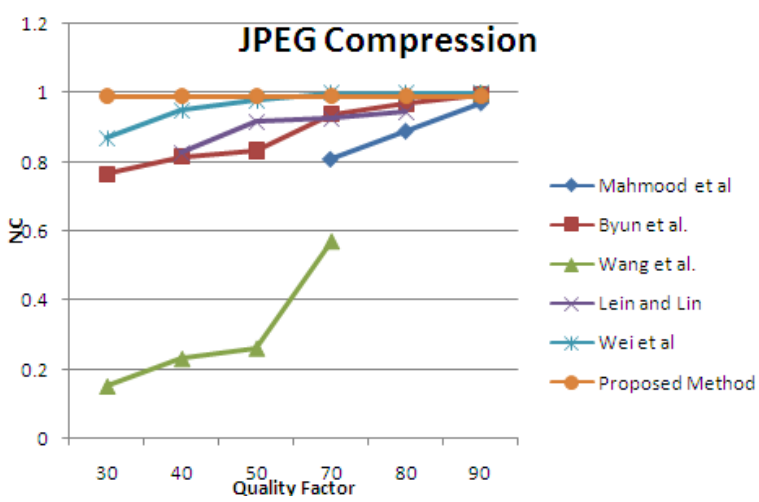

(a)

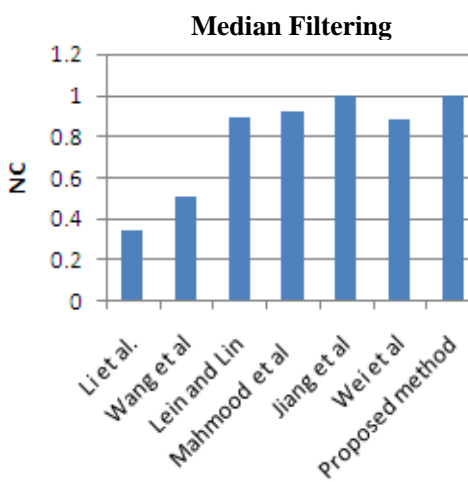

(b)

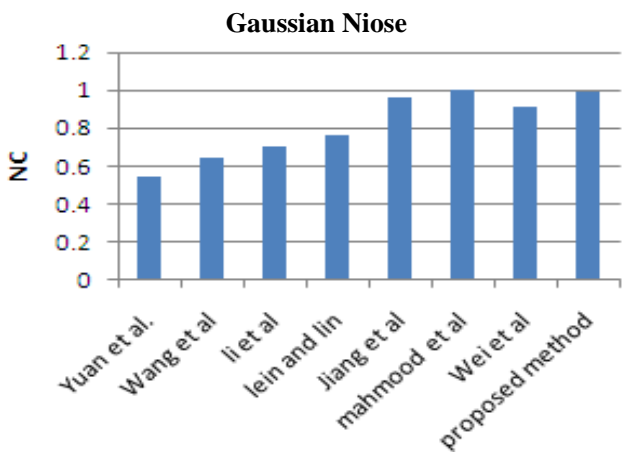

(c)

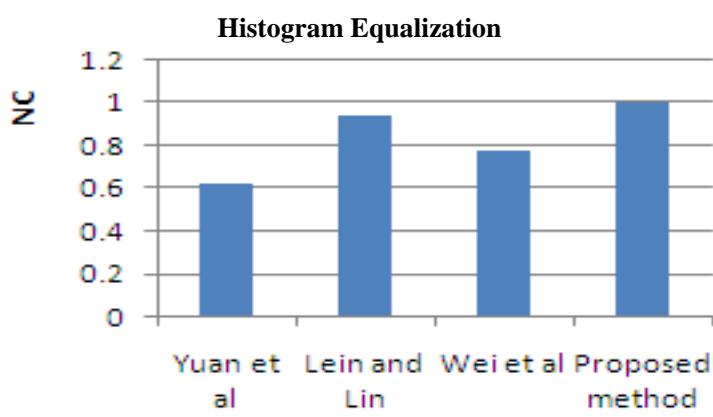

(d)

Fig. 17. (a) JPEG Compression; (b) Median Filtering;

(c) Gaussian Noise; (d) Histogram Equalization
TABLE XII: Comparison of Proposed Method and Existing Methods UNDER GEOMETRIC ATTACKS

(a) ROTATION

\begin{tabular}{ccccc}
\hline \hline Rotation & Li et al & Wang et al & Lein and lin & Proposed method \\
\hline 0.25 & 0.46 & 0.31 & 0.88 & 0.9942 \\
\hline 0.5 & 0.38 & 0.29 & 0.859 & 0.9939 \\
\hline 0.75 & 0.36 & 0.26 & 0.808 & 0.9939 \\
\hline 1 & 0.33 & 0.24 & 0.794 & 0.9937 \\
\hline \hline
\end{tabular}

(b) CROPPING

\begin{tabular}{ccccccc}
\hline \hline & $\begin{array}{c}\text { Li et } \\
\text { al }\end{array}$ & $\begin{array}{c}\text { Jiang } \text { et } \\
\text { al }\end{array}$ & $\begin{array}{c}\text { lein and } \\
\text { lin }\end{array}$ & $\begin{array}{c}\text { Yuan } \text { et } \\
\text { al. }\end{array}$ & $\begin{array}{c}\text { Wei et } \\
\text { al }\end{array}$ & $\begin{array}{c}\text { Proposed } \\
\text { Method }\end{array}$ \\
\hline Cropping & 0.61 & 0.6784 & 0.88 & 0.943 & 0.7 & 0.9921 \\
\hline \hline
\end{tabular}

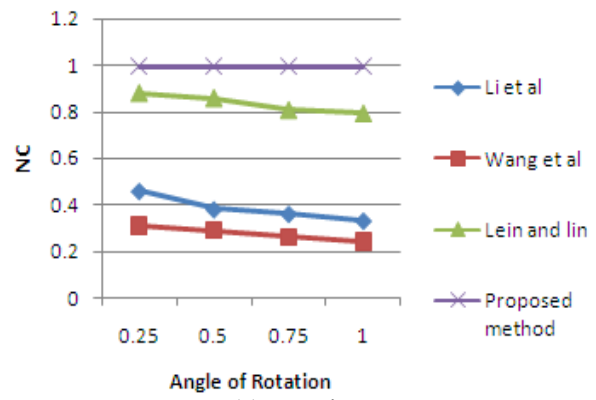

(a) Rotation

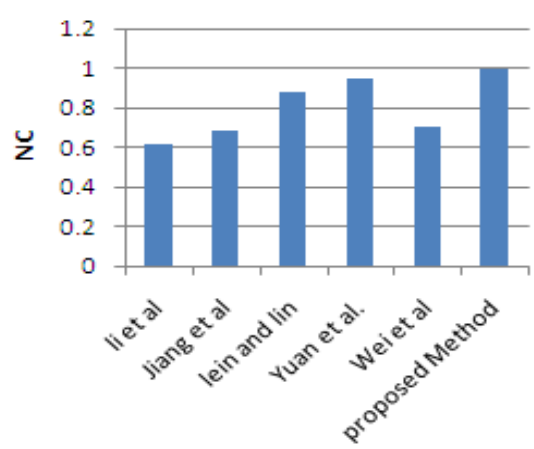

(b) Cropping

Fig. 18. (a)Rotation; (b)Cropping

From Figs.17 and 18, we can see the PSNR of the watermarked image and the robustness of watermark are far better than those existing methods. The authors claim their method can effectively resist image processing attacks like JPEG compression, median filtering, histogram equalization, addition of noise and geometric attacks like rotation, cropping and can obtain a higher PSNR of the watermarked image.

\section{CONCLUSION}

In this paper, a blind watermarking scheme based on Complex Double Haar Wavelet Transform was proposed. This included the advantages of both multi wavelet and complex representation of an image. Eigen values of the selected sub band are modified by the Eigen values of selected sub band of the binary watermark. During extraction process, watermark was extracted with the help of strength factor there was no need of the original host and watermark for extraction. Experimental results show that the proposed algorithm produced very high imperceptibility and very high robustness against various kinds of attacks like JPEG compression, histogram equalization, low pass filtering, 
median filtering, rotation, cropping and addition of noise like Gaussian, Salt\& Pepper, Speckle and Poisson noise. From the results of comparison with existing methods, we can believe that the proposed watermarking scheme achieves better imperceptibility and robustness in the watermarking world.

\section{REFERENCES}

[1] N. Nikolaidis, and I. Pitas, "Robust image watermarking in the spatial domain", International journal of signal processing, vol.66, no. 3, pp. 385-403, May 1998.

[2] Lei-Da and Bao-Long Guo, "Localised image watermarking in spatial domain resistant to geometric attacks", International journal of Electronics and communication, vol.63, no.2, pp. 123-131, February 2009.

[3] Chia-Chin Lin, Wei Liang Tai and Chin Chan Chang, "Multilevel reversible data hiding based on histogram modification of difference images", International journal of Pattern Recognition, vol.41, no.12, pp.3083-3096, December 2008.

[4] Juan R. Hernandez, Martin Amado and Fernando Perez-Gonazalez, "DCT domain watermarking techniques for still images:Detector performance analysis and a new structure", IEEE transactions on image processing, vol.9, pp. 55-68, Jan 2000.

[5] Vassilios Solachidis and Ioannis Pitas, "Circularly symmetric watermark embedding in 2-D DFT", IEEE transactions on image processing, vol.10, no.11, pp.1741-1753, Nov 2001.

[6] Yiwei Wang, John F. Doherty and Robert E. Van Dyck, "A wavelet based watermarking algorithm for ownership verification of digital images", IEEE transactions on image processing, vol.11, no.2, pp.77-88, Feb. 2002.

[7] Chirawat Temi, Somsak Choomchuay, and Attasit Lasakul, "A Robust Image Watermarking Using Multiresolution Analysis of Wavelet", Proc. of International symposium on communication and information technologies, vol.2, pp. 623-62, 2005.

[8] Shih Hao Wang and Yuan-Pei Lin, "Wavelet tree quantization for copyright protection watermarking", IEEE transactions on image processing, vol.13, no.2, pp. 126-144, Feb 2004.

[9] Kamaran Hameed, Adeel Mumtaz and S. A. M Gilani, "Digital image watermarking in the wavelet transform domain", Proceeding of World Academy of Science, Engineering and Technology(WASET), no.13, May 2006.

[10] Evelyn Brannock, Michael Weeks and Robert Harrison, "The Effect of Wavelet Families on Watermarking", Journal of Computers, vol. 4, no. 6, pp. 554-566, June 2009.

[11] K. Byun, S. Lee, and H. Kim, "A watermarking method using quantization and statistical characteristics of wavelet transform," Proc. IEEE, PDCAT, pp. 689-693, 2005.

[12] S. H. Wang and Y. P. Lin, "Wavelet tree quantization for copyright protection watermarking," IEEE Tran. Image Process., vol. 13, no. 2 , pp. 154-165, Feb. 2004.

[13] M. Jiang, G. Xu, and D. Yuan, "A novel blind watermarking algorithm based on multiband wavelet transform," Proc. IEEE ICSP, pp.857-860, 2004.

[14] Y. Yuan, H. Decai, and L. Duanyang, "An integer wavelet based multiple logo-watermarking scheme," Proc. IEEE IMSCCS, pp. 175-179, 2006.

[15] A. K. Mahmood and A. Selin, "Spatially Adaptive Wavelet Thresholding for Image Watermarking," in Proc. IEEE ICME, Toronto, ON, Canada, pp. 1597-1600, 2006.

[16] E. Li, H. Liang, and X. Niu, "Blind Image watermarking scheme based on wavelet tree quantization robust to geometric attacks," Proc. IEEE WCICA, pp. 10256-10260, 2006.

[17] B. K. Lien and W. H. Lin, "A watermarking method based on maximum distance wavelet tree quantization," in Proc. 19th Conf. Computer ,Vision, Graphics and Image Processing, 2006, pp. 269-276.

[18] Wei-Hung Lin, Shi-Jinn Horng, Tzong-Wann Kao, Pingzhi Fan, Cheng-Ling Lee and Yi Pan, "An Efficient Watermarking Method Based on Significant Difference of Wavelet Coefficient Quantization", IEEE Transactions on Multimedia, vol. 10, No. 5, pp.746-757, August 2008.
[19] S. Mallat, "A Wavelet Tour of Signal Processing", Academic Press, New York, 1999.

[20] Nick. Kingsbury, "Dual tree complex wavelet transform", IEEE magazine on signal processing, 2005.

[21] Mabtoul. S, Ibn Elhaj. E and Aboutajdine, "A robust digital image watermarking method using Dual Tree Complex Wavelet Transform", IEEE Symposium on Computers and Communications (ISCC), pp. 1000 - 1004, September 2008 .

[22] S. Maheswari and K. Rameshwaran, "Complex wavelet transform based adaptive multiple watermarking algorithm for images", CiiT International journal of digital image processing, vol.3, no.5, pp.305-308, March 2011.

[23] T. Nguyen, and P. P. Vaidyananthan, "Structures for M-channel prefect-reconstruction FIR QMF Banks which yield linear-phase analysis filters", IEEE Trans. Acoust., Speech, Signal Process., vol.38, no.3, pp. 433-446, March 1990.

[24] Xin Wang, "Moving Window-Based Double Haar Wavelet Transform for Image Processing", IEEE Transactions on image processing, vol.15, no.9, pp. $2771-2779$, September 2006.

[25] Ramakrishna Kakarala and Philip O. Ogunbona, "Signal Analysis Using a Multi resolution Form of the Singular Value Decomposition", IEEE Transactions on image processing, vol.10, pp. 5, May 2001.

[26] Gaurav Bhatnagar and Balasubramanian Raman, "A new robust reference watermarking scheme based DWT-SVD", Computer standards and interfaces, vol.31, no.5, pp. 1002-1013, September 2009.

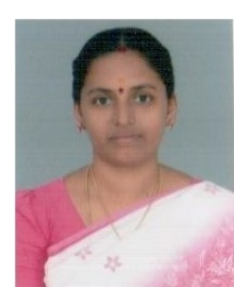

S. Maheswari Received the B.E degree in Electrical and Electronics Engineering and M.E degree in Applied Electronics from V.M.K.V. Engineering College, Salem, TamilNadu on 2001 and 2005 respectively. She has been doing Ph.D (part time) Anna University of Technology, Coimbatore. She worked as a lecturer in EEE department in V.M.K.V. Engineering College from 2002 to 2003.Then she worked as a lecturer in EEE department in Vivekanandha College of Engineering for women 2005-2007. Later she worked as an assistant professor in ECE department in K.S.R. College of Engineering from 2007 to 2010. Now she has been working as an assistant professor in EEE department in kongu Engineering College, Perundurai, Erode-638 052. TamilNadu, India. She has presented three papers in International conference and one paper in International Journal. She got the BEST PAPER award for a paper presented in International conference which was conducted by Sri Shakthi Institute of Technology on $10-11^{\text {th }}$ January 2010. Her current research interests are in the areas of wavelet analysis, watermarking, information security and image processing.

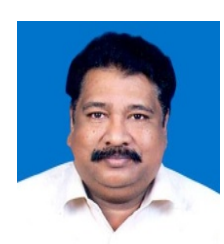

K. Rameshwaran obtained his B.E. degree in Electronics \& Communication Engineering from the University of Madras in 1980. He obtained his M.E.degree in Electronics Engineering from Anna University, Chennai in 1982 and his Ph.D. degree from I.I.T.Madras, Chennai. He started his professional career with a brief stint at I.I.T. Madras during 1982-1983 as a Project Engineer. He joined the department of Electrical Engineering at the Thiagarajar College of Engineering, Madurai as an Associate Lecturer in July 1983. Later, he joined the department of Electronics and Communication Engineering at the erstwhile Regional Engineering College (Presently known as National Institute of Technology), Tiruchirappalli in 1987. During the period between July 2006 and June 2008, he worked as the Principal of K.S.R. College of Engineering, Tiruchengode in Namakkal(District), Tamilnadu. Consequent to his retirement on Voluntary basis (VRS) from NITT in December 2009, he joined as the Principal of R.M.K. Engineering College, Kavaraipettai-601 206 and worked for a brief period of 7 (Seven) months. Now he has been working as the principle of JJ College of Engineering and Technology, Ammapettai, Tiruchirappalli-620 009. He has published several research papers in International and National Journals. He has also presented research papers in National and International conferences. His areas of interest are: Digital system and Microprocessors, Digital Filters and Control theory. 